\title{
Caracterização de Ocorrência Mineral de Cobre na Formação Maricá com Geocondutivímetro FDEM-GCM e Sensoriamento Remoto, Caçapava do Sul, RS
}

Vinícius Fani Souza Valon ${ }^{1}$; José Pedro Rebés Lima'; Marco Antonio Fontoura Hansen"; Cesar Augusto Moreira ${ }^{2}$; Henrique Garcia Pereira ${ }^{2}$

${ }^{1}$ GEOPAMPA - Campus Caçapava do Sul - Universidade Federal do Pampa - UNIPAMPA

${ }^{2}$ GEOPAMPA - Universidade Estadual Paulista "Júlio de Mesquita Filho" - UNESP

Copyright 2014, SBGf - Sociedade Brasileira de Geofísica

Este texto foi preparado para a apresentação no VI Simpósio Brasileiro de Geofísica, Porto Alegre, 14 a 16 de outubro de 2014. Seu conteúdo foi revisado pelo Comitê Técnico do VI SimBGf, mas não necessariamente representa a opinião da SBGf ou de seus associados. É proibida a reprodução total ou parcial deste material para propósitos comerciais sem previa autorização da SBGt.

\section{Abstract}

This paper shows the results of the electromagnetic method Geocondutivímeter (FDEM-GCM) and Remote Sensing applied to mineral prospecting of copper minerals. The goal is to map fracture zones containing potential copper mineralization. The survey was conducted in the rural zone of Caçapava do Sul municipality (RS), and the copper occurrences are at Marica Formation as carbonates of copper as Azurite and Malachite filling fault and pores of the host rock. As results were identified fault zones and fractures associated with the occurrence of copper ores. From these results a geological-geophysical model of the study area was elaborated.

\section{Introdução}

A necessidade de caracterização das novas reservas traduz a importância da pesquisa mineral que compreende o uso de ferramentas diretas e indiretas de investigação.

O objetivo deste trabalho consiste em mapear zonas de falhas e fraturas, possivelmente associadas com presença de minerais metálicos, através da aplicação e integração de técnicas de Sensoriamento Remoto e Método Geofísico Eletromagnético de investigação rasa, Geocondutivímetro (FDEM-GCM) motivado pela vocação econômica da região devido às ocorrências de cobre.

A metodologia aplicada neste trabalho é complementar ao que já foi proposto em estudos anteriores (Garrido, 1978; Sá, 1981; Pereira, 2011; Cesar e Ilha, 2011) integrando no estudo o método Sensoriamento Remoto para ressaltar os lineamentos estruturais (Bitencourt, 2011).

A área de estudo está localizada na zona rural do município de Caçapava do Sul (RS), situando-se à Noroeste do município, na localidade conhecida por Capão Grande. $O$ acesso à região se dá primeiramente pela rodovia federal BR-392 e posteriormente passando um trevo segue-se ao oeste pela BR-290 até a localidade Cerrito do Ouro, onde se direciona para sul numa estrada secundária e segue até a área de estudo, conforme o mapa da figura 1 .

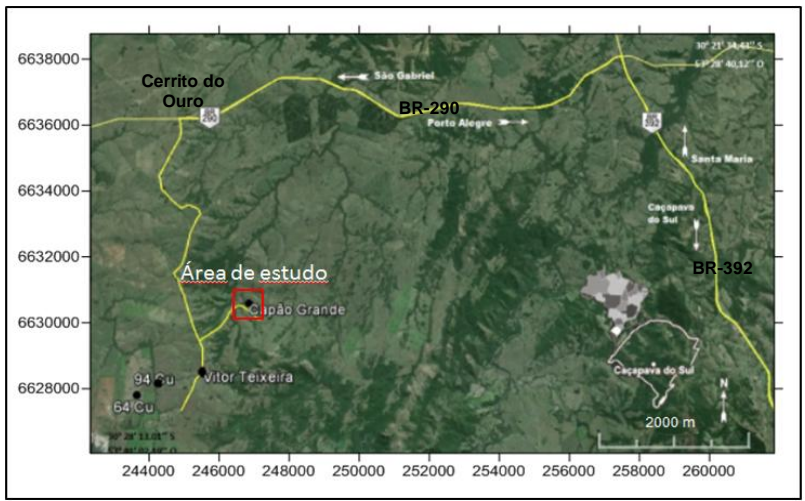

Figura 1 - Localização da área de estudo.

$\mathrm{Na}$ folha Passo do Salsinho foram cadastradas cinco ocorrências e um indício de mineralização cuprífera, todos descritos em trabalhos precedentes (Bocchi, 1970; Ribeiro e Fantinel, 1978) e pesquisados em detalhe pelo Serviço Geológico do Brasil-CPRM (Porcher, 1995).

Na figura 2 estão representados os litotipos presentes na área são representados pelo Complexo Metamórfico Vacacaí, Grupo Bom Jardim (Unidade Passo da Promessa), Formação Acampamento Velho Unidade Cerro do Bugio (Porcher, 1995). Os arenitos representados pela Formação Passo da Promessa são caracterizados por níveis conglomeráticos, onde os seixos são predominantemente de rochas graníticas e metamórficas, como granitos, gnaisses, quartzitos, xistos, anfibolitos e sua coloração é predominantemente avermelhada.

$\mathrm{Na}$ área de estudo ocorre um afloramento de direção nordeste, com aproximadamente 20 metros de comprimento por dois metros de largura, se salientado no relevo da área de estudo. As mineralizações de cobre presentes neste afloramento estão em grande parte nos interstícios e fraturas das rochas expostas (Bocchi, 1970). A mineralização é constituída principalmente de carbonatos de cobre, especialmente Malaquita e Azurita. 


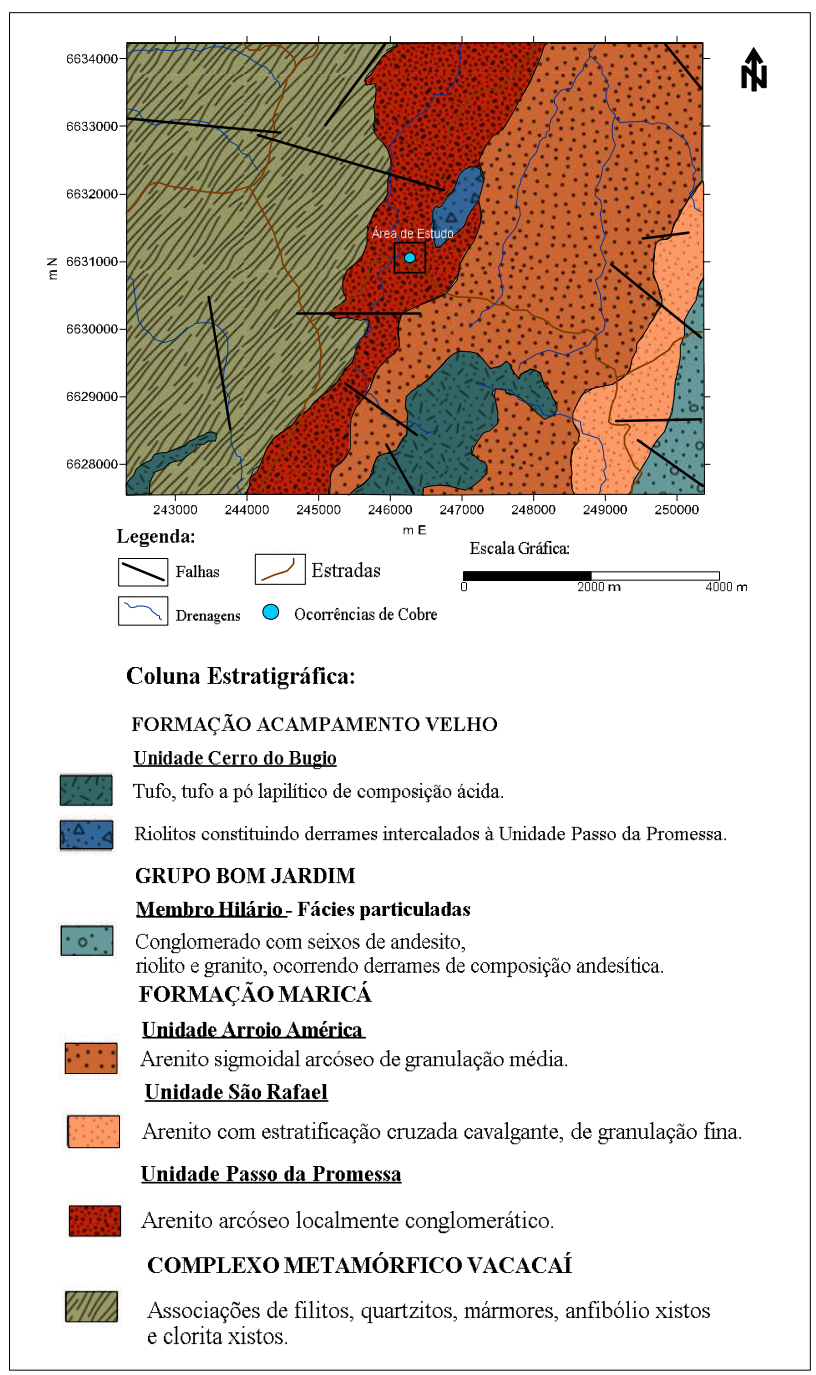

Figura 2 - Mapa Geológico da região de estudo (modificado de Porcher, 1995).

\section{Métodos}

O emprego de imagens de satélite teve o objetivo de identificar os lineamentos estruturais existentes na região de estudo, que podem estar associados à ocorrência de cobre. Desta forma foi feito o recorte da área de estudo, onde a resolução espacial é de $30 \mathrm{~m}$ por $30 \mathrm{~m}$ para cada pixel. Foi criado um banco de dados contendo sete bandas espectrais, que foram posteriormente importadas e registradas com os respectivos dados das posições geográficas realizadas a partir de pontos obtidos com GPS.

Após o georreferenciamento foi feita a aplicação da técnica de filtragem para a análise das componentes principais. Os filtros do tipo passa-alta direcionais têm como maior aplicação nos estudos geológicos a identificação e análise de lineamentos, pois os mesmos são utilizados visando o realce das feições em diferentes direções.
Método Eletromagnético Geocondutivímetro (FDEMGCM)

A técnica utilizada para aquisição de dados foi de caminhamento eletromagnético, que consiste no deslocamento conjunto das bobinas de recepção e transmissão separadas a uma distância constante, segundo uma posição constante dos eixos dos dipolos.

O Sistema EM-34 é constituído de duas bobinas que são conectadas entre si com distâncias, que podem ser variáveis de acordo com a profundidade que se deseja investigar. Possuem um sistema transmissor e receptor que são móveis e conectados diretamente em cada uma das bobinas, que podem ser utilizadas na posição vertical (dipolo horizontal) e na posição horizontal (dipolo vertical), podendo abranger uma profundidade mínima de $7,5 \mathrm{~m}$ e máxima de $60 \mathrm{~m}$, com a vantagem de não precisar de contato físico com o terreno (Figura 3).

Inicialmente foi estipulada uma região de estudo, onde o alvo é uma das ocorrências de cobre, que foi determinada após a obtenção dos lineamentos obtidos a partir do Sensoriamento Remoto. As medições com o método geofísico Geocondutivímetro (FDEM-GCM) foram realizadas em quatro perfis de caminhamentos eletromagnéticos para duas distâncias entre bobinas, que no presente caso será $10 \mathrm{~m}, 20 \mathrm{~m}$ e $40 \mathrm{~m}$, perfis paralelos de extensão aproximada em $540 \mathrm{~m}$ e $60 \mathrm{~m}$ de distância entre si.

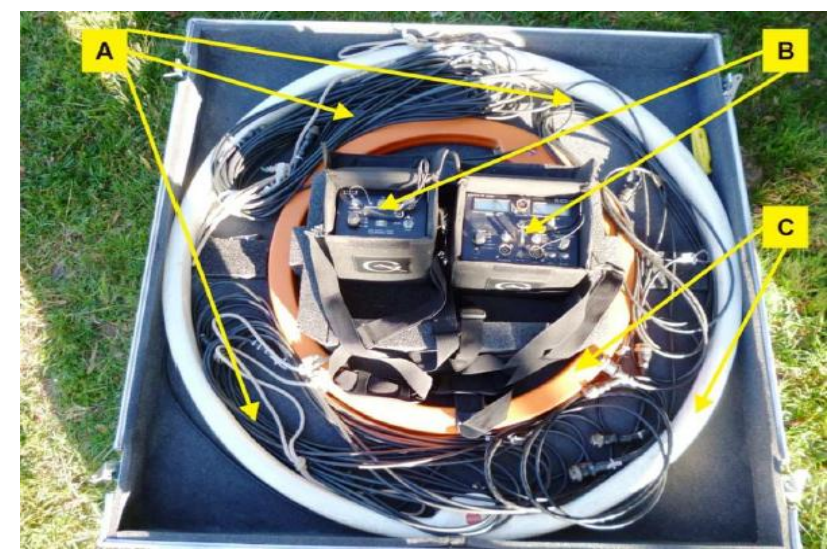

Figura 3 - Equipamento EM-34XL, onde: A) Cabos de separação entre as bobinas: $10 \mathrm{~m}, 20 \mathrm{~m}$ e $40 \mathrm{~m}$; B) Transmissor à direita e Receptor à esquerda. C) Bobina transmissora (branca) e receptora (laranja).

\section{Resultados}

Em termos de Sensoriamento Remoto a aplicação de filtragem evidenciou uma tendência preferencial na direção NW-SE e NE-SW, e estas direções foram importantes para se basear a aplicação do método eletromagnético Geocondutivímetro (FDEM-GCM) perpendicularmente as estruturas encontradas. Foram extraídos, conforme a figura 4, 395 lineamentos estruturais. 


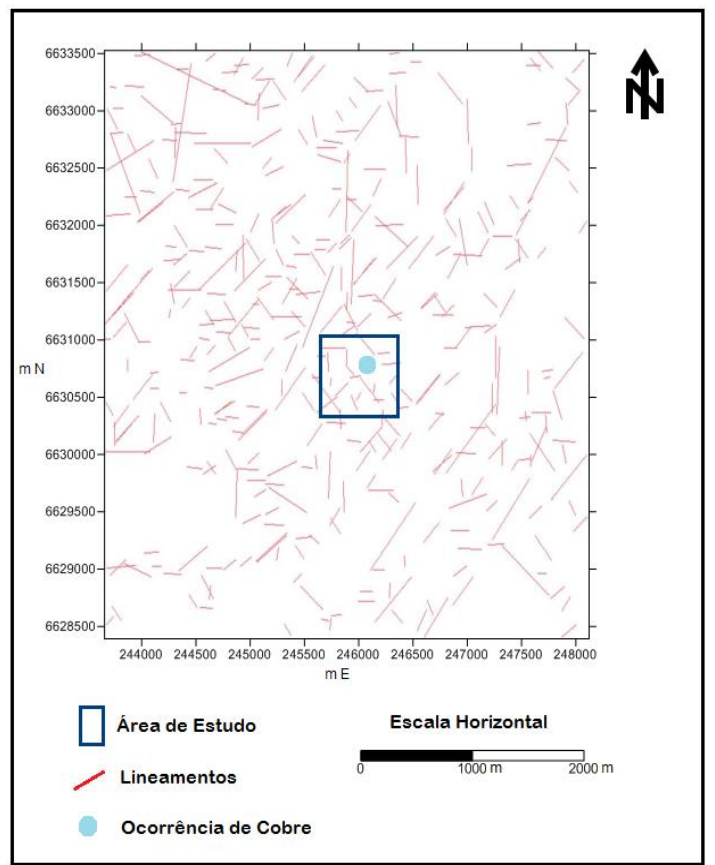

Figura 4 - Mapa de lineamentos tectônicos identificados na região de estudo por sensoriamento remoto.

Os diagramas de Rosetas indicam as direções preferenciais dos lineamentos tectônicos identificados em toda a área de aplicação do Sensoriamento Remoto. Os diagramas confirmam a forte presença de estruturas de direções NE-SW (Figura 5).

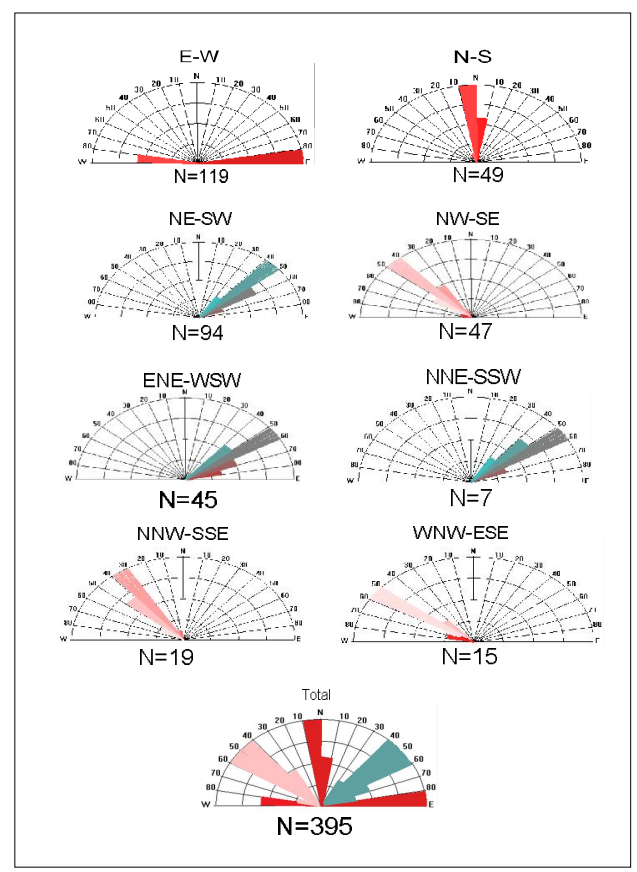

Figura 5 - Diagramas de rosetas com as direções de lineamentos extraídos por Sensoriamento Remoto.

Após os diagramas de rosetas confirmarem as direções preferenciais das fraturas em maior quantidade para direção E-W e NE-SW, foi determinado que os perfis fossem realizados ortogonais às direções preferenciais de preenchimento de minérios de cobre como Malaquita e Azurita, ou seja nas direções NW-SE na área de estudo.

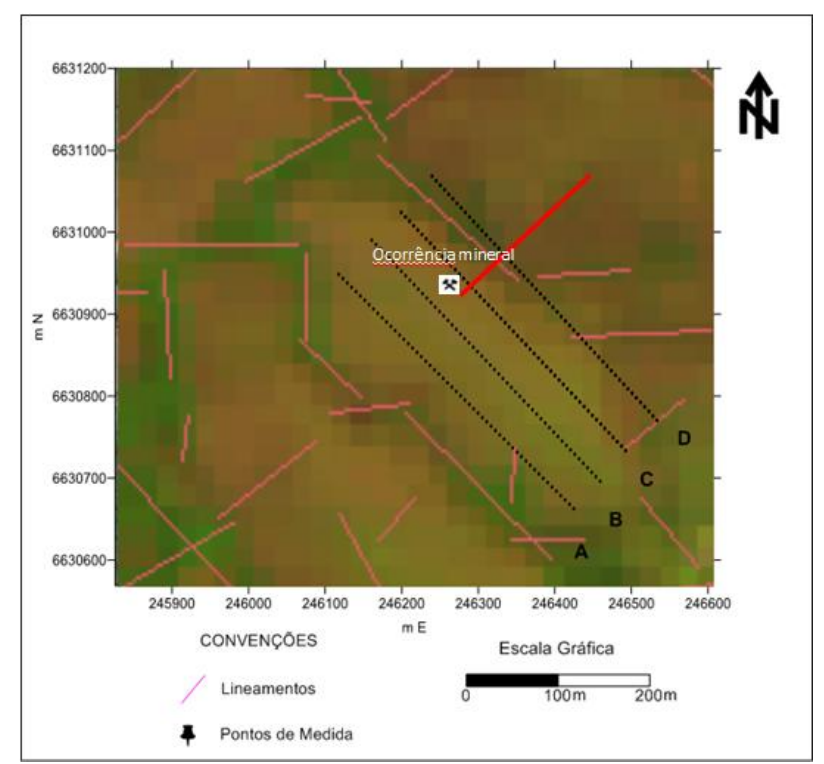

Figura 6 - Perfis A, B, C e $D$ realizados ortogonalmente à direção de lineamento e afloramento com ocorrência mineral de carbonato de cobre (linha vermelha mais intensa).

É de se esperar um contraste de propriedades físicas nesse contexto geológico, já que os minerais constituintes do arcabouço da rocha encaixante, no caso da área de estudo pertence à Formação Maricá unidade Passo da Promessa sendo caracterizados por baixa condutividade e os minerais metálicos de cobre apresentam alta condutividade. Os dados de condutividade aparente são apresentados na forma de pseudosseções em corte.

As pseudosseções de condutividade aparente descrevem valores variáveis entre 3 e $22 \mathrm{mS} / \mathrm{m}$. Os valores baixos são representados por cores frias, enquanto que os valores mais altos são representados por cores quentes (Figura 7).

O perfil $A$ foi realizado a uma distância de $120 \mathrm{~m}$ à sudoeste do ponto de afloramento com presença de carbonatos de cobre. Neste perfil se percebe valores crescentes de condutividade aparente de baixo para cima, dando a entender que na região deste perfil os fatores que contribuem para o aumento nos valores de condutividade estão na parte mais superficial, em profundidades de até $40 \mathrm{~m}$, desta forma percebe-se uma extensa camada mais condutiva na parte mais superficial, em toda extensão do perfil.

Nos pontos de medida correspondentes a $90 \mathrm{~m}, 260 \mathrm{~m}$, $330 \mathrm{~m}$ e $340 \mathrm{~m}$ e entre $500 \mathrm{~m}$ e $530 \mathrm{~m}$, é possível perceber que litologia presente em maiores profundidades apresentou valores de condutividade aparente baixa, característica de embasamento. Esta 
litologia é seccionada por zonas mais condutivas apresentando características de presença de fraturas ou falhas preenchidas por minerais metálicos. Em contra partida, se observa alguns pontos menos condutivos intrudindo a camada mais condutiva, como é o caso das distâncias $90 \mathrm{~m}, 340 \mathrm{~m}$ e $470 \mathrm{~m}$, podendo estar representando uma alternância entre o solo e uma rocha menos condutiva.

O ponto mais significativo em termos de condutividade está no início do perfil com a presença de uma zona quase laranja, o que possibilita dizer que a condutividade atinge valor de até $20 \mathrm{mS} / \mathrm{m}$.

O perfil B foi realizado a $60 \mathrm{~m}$ na direção sudoeste do afloramento com minérios de cobre. Assim como no perfil anterior os maiores valores de condutividade aparente estão representados na faixa mais superficial do terreno, porém a diferença está nas variações mais frequentes em relação ao perfil A. É possível perceber trechos mais extensos na região do embasamento com maiores valores de condutividade, como é o caso dos pontos de 0 $\mathrm{m}$ a $40 \mathrm{~m}, 100 \mathrm{~m}$ a $140 \mathrm{~m}, 200 \mathrm{~m}$ a $230 \mathrm{~m}$ e $500 \mathrm{~m}$. Na parte superficial se percebe também a presença de material menos condutivo em meio à camada mais condutiva na distância $350 \mathrm{~m}$ no perfil. Por fim. o que chama a atenção é uma região anômala na posição $60 \mathrm{~m}$ até $80 \mathrm{~m}$ do perfil com altos valores de condutividade na ordem de $20 \mathrm{mS} / \mathrm{m}$.

$\mathrm{O}$ perfil $\mathrm{C}$, que passa ao lado do afloramento com minerais de cobre apresenta valores altos de condutividade aparente. A partir da presença de zonas mais condutivas infere-se a presença de três falhas. Essas falhas podem estar associadas a evento da remobilização hidrotermal, capaz de originar minérios a partir do fluxo de fluidos (Porcher, 1995). No ponto de medição $240 \mathrm{~m}$ percebe-se um encurtamento da zona menos condutiva e predominância de litologia mais condutiva podendo este fato estar associado à presença dos minérios de cobre em subsuperfície de até $30 \mathrm{~m}$. Em seguida se observa uma variação de uma zona pouco condutiva para mais condutiva indicando um provável aumento da concentração dos minérios de cobre na rocha encaixante (arenitos falhados). Após o afloramento encontra-se uma parte menos condutiva podendo ser a rocha encaixante com teores baixos de minérios.

$\mathrm{O}$ perfil $\mathrm{D}$ foi realizado a $60 \mathrm{~m}$ de distância do perfil $\mathrm{C}$ com direção a nordeste do afloramento com minérios de cobre. Neste perfil a exemplo dos anteriores ocorrem zonas condutivas associadas a presença de falhas com possível presença de minerais metálicos. Estas falhas foram inferidas entre $0 \mathrm{~m}$ e $50 \mathrm{~m}, 140 \mathrm{~m}$ e $300 \mathrm{~m}$ do perfil. Existem algumas litologias mais superficiais menos condutivas, que podem ser compreendidas como rochas encaixantes dos minérios de cobre, porém com pouca concentração dos mesmos naquele ponto, como é o caso da parte mais superficial no ponto $300 \mathrm{~m}$.

$\mathrm{Na}$ figura 8 têm-se os mapas de superfícies, onde os valores de condutividade aparente são referentes a diferentes profundidades. As falhas inferidas a partir dos perfis em corte, ilustrados na figura 7, estão evidenciadas em cada plano. Observa-se controle das falhas na forma de distribuição dos valores de condutividade aparente nos níveis de maior profundidade $30 \mathrm{~m}$ e $60 \mathrm{~m}$.

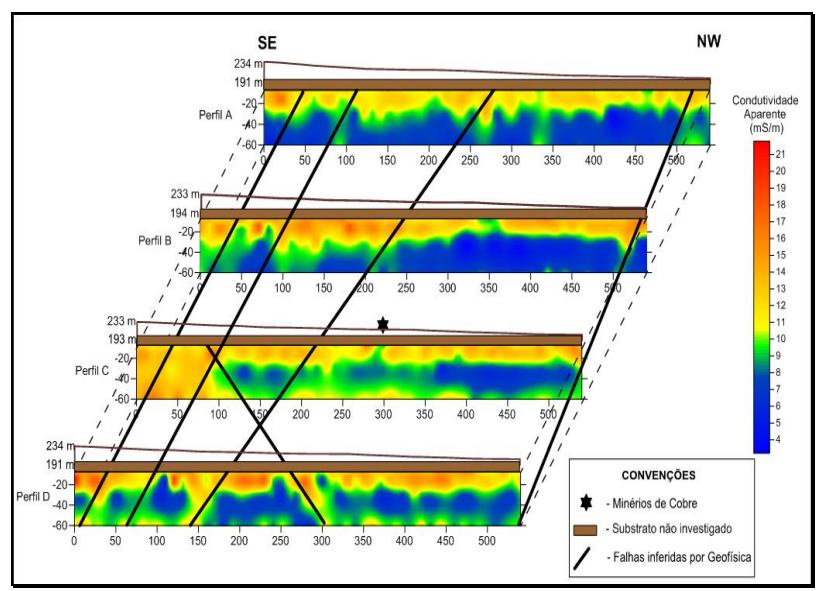

Figura 7 - Perfis A, B, C e D: Pseudosseção de Condutividade Aparente.

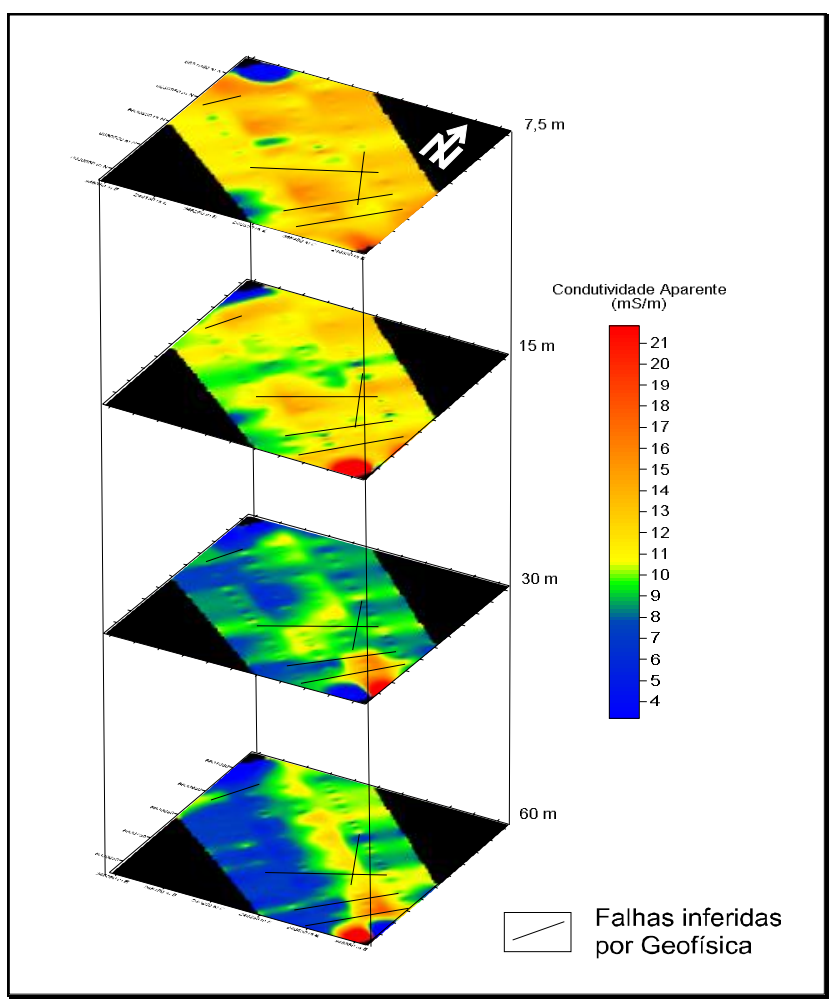

Figura 8 - Mapas de superfícies de condutividade aparente, em diferentes profundidades $(7,5 \mathrm{~m}, 15 \mathrm{~m}, 30$ $m$ e $60 \mathrm{~m}$ ) e respectivas falhas associadas.

A 7,5 $\mathrm{m}$ de profundidade se observa uma grande zona condutiva, que se refere à condutividade de provável presença de sulfetos disseminados, que é indicada pela cor amarela entre 10 e $14 \mathrm{mS} / \mathrm{m}$. É perceptível alguma 
litologia quase aflorante com valor de condutividade na tonalidade verde, que corresponde valores entre 9 e 10 $\mathrm{mS} / \mathrm{m}$, podendo ser caracterizada pelos arenitos da Formação Maricá, que na área de estudo é representado pela unidade Passo da Promessa, de composição arcoseana. A tonalidade azul representa o embasamento do Complexo Metamórfico Vacacaí, que segundo Porcher (1995), corresponde a associações de filitos, quartzitos, mármores, anfibólio xistos e clorita xistos, gerando respostas ainda mais baixas nos valores de condutividade aparente. De acordo com os resultados obtidos, os valores tendem a diminuir, com o aumento da profundidade, evidenciando a presença do embasamento a partir de $30 \mathrm{~m}$ de profundidade.

No quadrante sudeste dos planos de superfície a partir de 7,5 $\mathrm{m}$ fornecem informações de um corpo condutivo, que pode ser interpretado como a presença de minérios de cobre ou outros metálicos, representando valores anômalos dos que são vistos nas outras partes dos planos de superfície, sendo controladas por falhas de direção NE-SW preferencialmente. Os valores de condutividade aparente tendem a diminuir com a profundidade, à medida que se aproxima do embasamento de rochas metamórficas. Observa que a $30 \mathrm{~m}$ de profundidade os valores de condutividade aparente são mais altos no quadrante sudeste $e$, provavelmente estão associados a um corpo intrusivo mineralizado que corta os arenitos arcoseanos da Formação Maricá.

A $60 \mathrm{~m}$ de profundidade, o material condutivo está intrusivo também em rochas do embasamento Metamórfico do Complexo Vacacaí. Desta forma se tem presença de minerais metálicos em algumas porções controladas por zonas de falhas e em maior parte disseminadas nas rochas sedimentares da Formação Maricá. A provável presença destes minérios também estão em rochas do embasamento, indicando algo já mencionado na literatura, pois, os jazimentos de cobre também estão associados às litologias encaixadas em litotipos do Cinturão Metavulcanossedimentar (Porcher, 1995), no caso representando o embasamento na área de estudo.

De acordo com resultados obtidos a partir dos perfis em corte e dos mapas de superfície foi confeccionado um modelo geológico-geofísico do comportamento da geologia de subsuperfície na área de estudo. Este modelo pode ser visto na figura 9 .

O sistema de falhas foi inferido a partir dos resultados fornecidos com os levantamentos de campo e extração de lineamentos, utilizando as técnicas de sensoriamento remoto. A partir das pseudosseções de condutividade aparente foi realizada a correlação entre os valores que podem caracterizar zonas condutivas indicativas da presença de falhas (Lima et al., 2009). Em alguns pontos estes locais como no início do perfil C, ficou evidenciada a presença de minerais metálicos, indicada pelo alto valor de condutividade em uma grande extensão, porém o afloramento com carbonato de cobre e sulfetos afloram a $250 \mathrm{~m}$ deste ponto mais condutivo. Possivelmente a explicação para este fato seja que 0 evento de remobilização hidrotermal, que origina as concentrações mais altas de minerais metálicos nas rochas, tenha sofrido influencia dos processos evolutivos de formação do relevo da região.

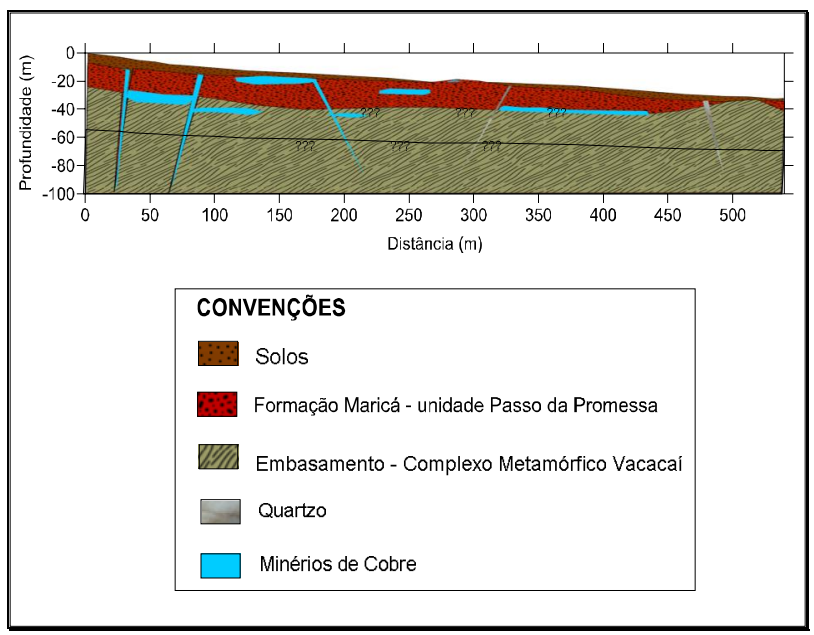

Figura 9 - Modelo geológico-geofísico da área de estudo.

Foram obtidos valores de condutividade em quatro zonas, verificadas a partir dos mapas de superfície de condutividade aparente, onde ocorrem valores mais baixos em maiores profundidades, caracterizando o embasamento na região formado pelas rochas do Complexo Metamórfico Vacacaí. Verificou-se também uma região de valores mais altos indicando a presença de rochas da Formação Maricá, que nos afloramentos com minérios de cobre se apresentou como a rocha encaixante dos mesmos, que nos dados são representados como a litologia mais condutiva. Os valores obtidos nas regiões mais superficiais são referentes à condutividade do solo sobrepostos as rochas da Formação Maricá, unidade Passo da Promessa.

\section{Conclusões}

A partir da identificação dos lineamentos tectônicos obtidos pelo sensoriamento remoto, juntamente com os resultados obtidos dos perfis eletromagnéticos ortogonais ao lineamento associado ao afloramento com minérios de cobre. Verificou-se a identificação de contrastes entre as rochas mineralizadas e as encaixantes, permitindo realizar uma estimativa de continuidade lateral e em profundidade da ocorrência de minérios de cobre.

Os dados geofísicos forneceram informações a respeito do comportamento das mineralizações na área de estudo, que ocorrem predominantemente disseminadas, como também associadas a zonas de falhas de direção NE-SW. 
Os resultados obtidos por sensoriamento remoto e pelo método eletromagnético geocondutivímetro propiciou a elaboração de modelo geológico-geofísico para a área de estudo.

\section{Agradecimentos}

Agradecemos a todos que contribuíram para a realização desta pesquisa e, em especial, a UNIPAMPA pelo fornecimento dos equipamentos.

\section{Referências}

Bitencourt, J.C. 2011. Aplicação do método Eletromagnético (FDEM-GCM) para caracterização geoelétrica de uma ocorrência cuprífera no município de Caçapava do Sul - RS. Monografia de Trabalho de ConclusUNIPAMPA. Caçapava do Sul-RS. 55p.

Bocchi, P. R. 1970. Geologia da Folha de Caçapava do Sul, Rio Grande do Sul. Rio de Janeiro: Departamento Nacional de Produção Mineral - DNPM. Boletim 245, 86 p.

Garrido, I. A. A. 1978. Estudos Geofísicos Detalhados da Área Sítio do Chico. Salvador: Dissertação de Mestrado. Universidade Federal da Bahia. 86p.

Lima, J.P.R. et al. 2009. Use of FDEM-GCM Method for Groundwater Prospecting in Crystaline. $11^{\text {th }}$ International Congress of the Brazilian Geophysical Society. Rio de Jenairo.

Moreira, C.A., Ilha, L.M. 2011. Prospecção geofísica em ocorrência de cobre localizada na bacia sedimentar do Camaquã (RS). REM:: R. Esc. Minas, Ouro Preto, 64(3), p. 305-311.

Pereira, H.G. 2011. Estudo geofísico em ocorrência de cobre por meio de métodos elétrico e eletromagnético, localizado no município de Caçapava do Sul (RS). Monografia de Trabalho de Conclusão de Curso. UNIPAMPA. Caçapava do Sul-RS. 78p.

Porcher, C.A. 1995. Folha Passo do Salsinho, Folha SH.22-Y-A-I-4, escala 1:50.000, Estado do Rio Grande do Sul. Programa Levantamentos Geológicos Básicos do Brasil, CPRM. Brasília. 372p.

Ribeiro M., Fatinel L.M. 1978. Associações petrotectônicas do Escudo Sul - Riograndense: Tabulação e distribuição das associações petrotectônicas do Escudo do Rio Grande do Sul. Inheríngia, Série Geologia, Porto Alegre, v.5. p. 19-54.

Sá, E. P. 1981. Levantamento geofísico integrado da área de Terra do sal, Curaçá-BA: Aplicação na reavaliação geológica visando à prospecção de cobre. Bahia: Dissertação de Mestrado. Câmara de Pesquisa e Ensino Pós-Graduação, Universidade Federal da Bahia. 